\title{
A study of foramen magnum and its clinical relevance
}

\author{
Arjun Kumar' ${ }^{1}$ Pratishtha Potdar ${ }^{2 *}$, Kuldeep Singh ${ }^{3}$, Jagmohan Singh Dhakar ${ }^{4}$ \\ ${ }^{1}$ Resident, ${ }^{\mathbf{2}}$ Associate Professor, ${ }^{3}$ Professor, ${ }^{4}$ Statistician cum Assistant Professor, ${ }^{1-3}$ Dept. of Anatomy, ${ }^{4}$ Dept. of Community Medicine, \\ ${ }^{1}$ Rama Medical College \& Research Institute, Kanpur, Uttar Pradesh, ${ }^{2,4}$ Santosh Medical College, Ghaziabad, Uttar Pradesh, ${ }^{3}$ Badaun \\ Medical College, Badaun, Uttar Pradesh, India
}

*Corresponding Author: Pratishtha Potdar

Email: drpratishthagupta@gmail.com

\begin{abstract}
Introduction: Foramen magnum is very important land mark as it is closely related with brainstem and spinal cord. Morphometric parameters of foramen magnum are required for forensic investigations \& anthropological identification of unknown individual. As there is paucity of literature regarding variations in size \& shape in reference to different races which prompted us for this study.

Aims and Objective: The aim was to study the morphology of foramen magnum that can be applied for many invasive surgical as well as diagnostic procedures, which carried out in brain.

Materials and Methods: In this cross sectional study, 50 adult human skulls were taken from the department of anatomy. Various parameters of foramen magnum like antero-posterior diameter, transverse diameter along with the measurement of area of dry human adult skull were calculated using vernier caliper to an accuracy of $0.1 \mathrm{~mm}$. Mean standard deviation and $\mathrm{p}$ value were also calculated. The distribution of shapes into oval, round, tetragonal, irregular, diamond were also assessed visually.

Results: The commonest shape found was oval followed by irregular. In this study on 100 sides of 50 dry Skulls the mean Antero-posterior diameter, Transverse diameter are as $34.08 \pm 2.25 \mathrm{~mm} \& 28.17 \pm 2.85 \mathrm{~mm}$. The measurement of area in foramen magnum of dry skull is $757.41 \pm 115.09 \mathrm{~mm}^{2}$. This data were then compared and analyzed with the various other studies.

Conclusion: The anatomical knowledge of Foramen magnum is of great importance for Neurologist, Radiologist \& Anthropologist to achieve the best exposure with appropriate surgical outcome.
\end{abstract}

Keywords: Foramen magnum, Skull, Anatomical variations, Morphometric analysis.

\section{Introduction}

The foramen magnum is wide oval opening in the posterior cranial fossa connecting the cranial cavity with the vertebral canal. It allow the passage of vital structures of brain through it. The margins of the foramen magnum is anteriorly encroached by the occipital condyles, which articulate with the superior articular facets of the atlas. ${ }^{1}$ The foramen magnum is protected by soft tissue mass inferiorly. ${ }^{2,3}$

The morphometric data of foramen magnum can be used for diagnosis of various congenital disease such as Arnold Chiari malformation in which expansion of transverse diameter more than anteroposterior diameter. ${ }^{4}$ The diameter of the foramen magnum are also needed prior to the surgery of the posterior cranial fossa lesions as greater contra lateral exposure required where antero-posterior diameter is more. The morphological parameters of the foramen magnum are more in males than in females, which can be utilize for differentiation of sex in various medicolegal conditions. ${ }^{5}$ Various studies shows of foramen magnum shows that the antero-posterior \& transverse diameter is $3.5 \mathrm{~cm} \mathrm{\&} 3 \mathrm{~cm}$. Compression of brainstem due to various pathological conditions causes life threatening respiratory complications. ${ }^{6,7}$ Studies of Foramen magnum in skull is very important in anthropology, anatomy, forensic \& various other field but the available data is scanty and is at variance with one another. ${ }^{8}$ So additional studies are required to form some standard parameters. Further, foramen magnum parameter index is also utilize for differentiations of races among skull. ${ }^{9}$ There also exist some racial relationship among different shapes of foramen magnum. ${ }^{10}$ Thus considering the above importance of foramen magnum, we calculate the antero-posterior diameter, transverse diameter along with the measurement of area in foramen magnum of dry human skull. We also analyze on variations of its shape, which can be utilize by Clinicians and Radiologist for various diagnostic procedures.

\section{Materials and Methods}

A cross sectional study was conducted in the department of Anatomy, Rama Medical College, from February 2017 to August 2017 after taking the ethical clearance from Institutional Ethical Committee. Study was done on 100 sides of 50 adult human dry skull. Complete dry skulls of age group between (18-70 yrs) were taken from department. The skulls that are broken or incomplete and those of children \& old age were excluded from the study. All dimensions of Foramen magnum in dry human skulls were measured with the help of Vernier calipers in an accuracy of $0.01 \mathrm{~mm}$. All dimensions were measured separately by two observer to prevent inter-observer error. The dimensions measured were includes the following:

\section{Anteroposterior diameter /Foramen magnum length (FML)}

Anteroposterior diameter is measured by taking a point on the middle of anterior margin to the point on the middle of posterior margin of the foramen magnum. Mean of two values were taken (Fig. 1). 


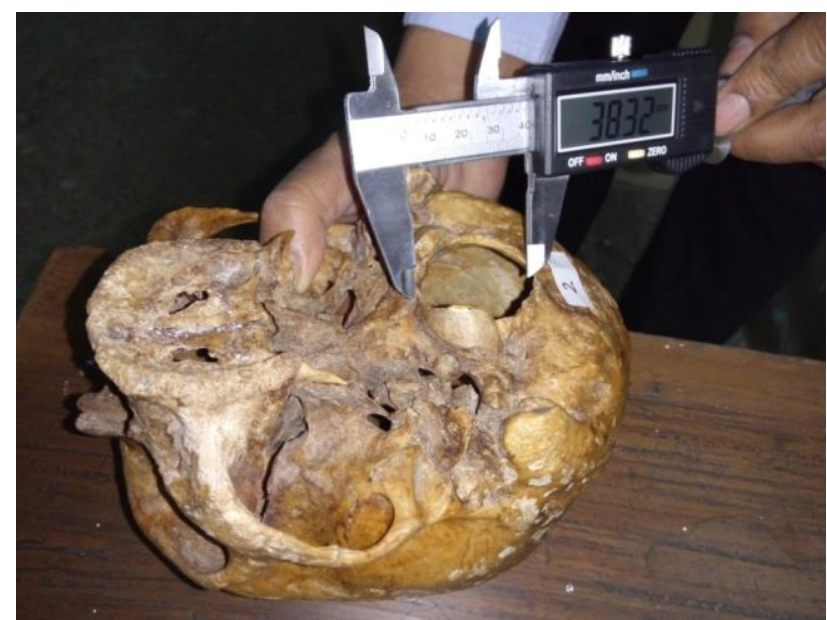

Fig. 1: Showing measurement of Antero posterior diameter

Transverse diameter/Foramen magnum width (FMW) The width of foramen magnum is taken by measuring most prominent parts of the lateral curvature as straight transverse diameter. (Fig. 2).

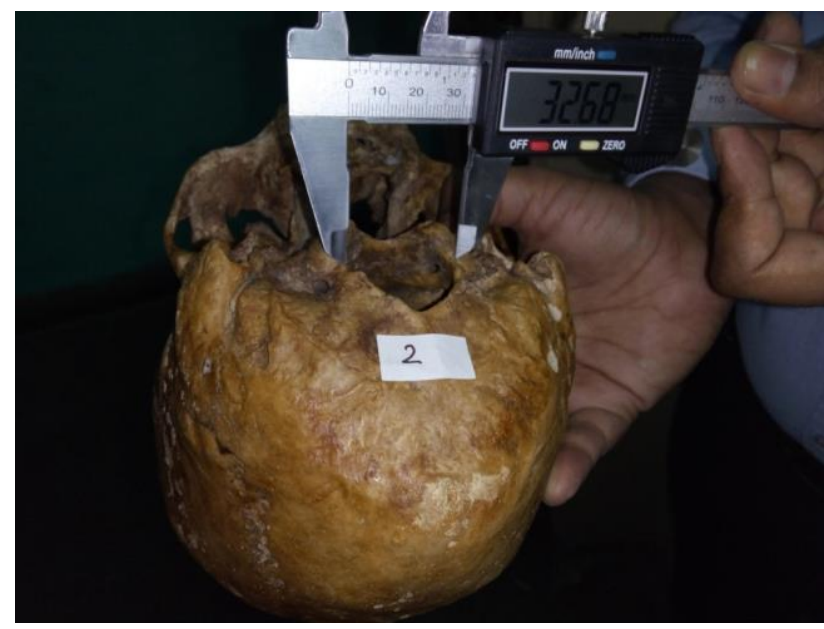

Fig. 2: Showing measurement of Transverse diameter

The two prongs of vernier calipers are fixed with screw over bony margins, of foramen magnum then the length and width were recorded over the graduated metallic scale.

\section{Foramen magnum Area (FMA)}

The area of Foramen magnum was calculated as described by Anil Kumar et $\mathrm{a}^{11}$ using Radinsky’s formula.

\section{Variation in Shapes of foramen magnum}

The frequency of distribution of various types of shapes were recorded (Fig. 3-6).

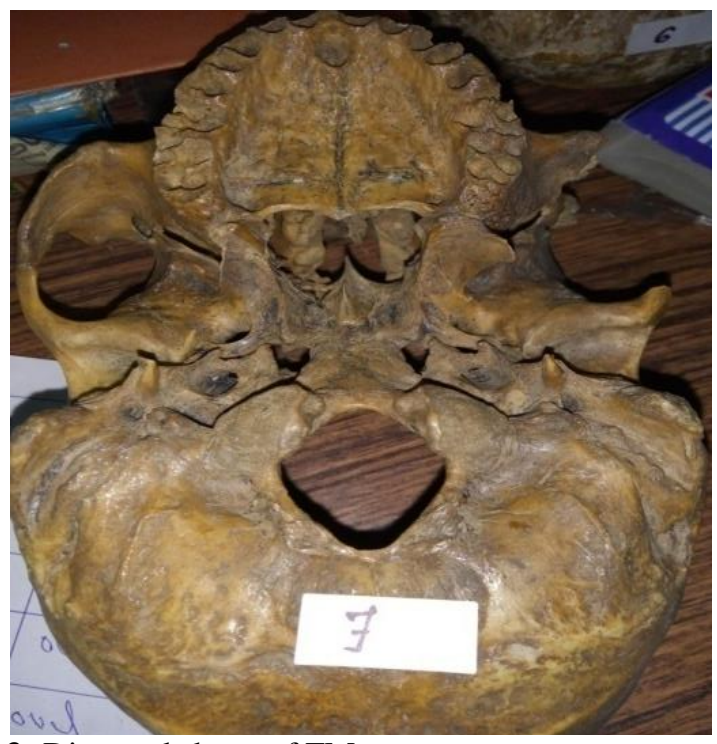

Fig. 3: Diamond shape of FM

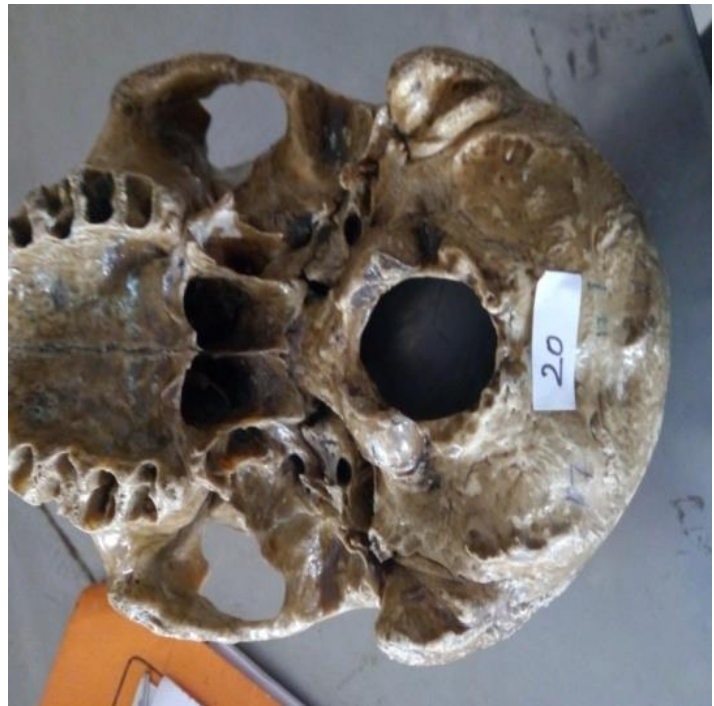

Fig. 4: Pentagonal shape of FM

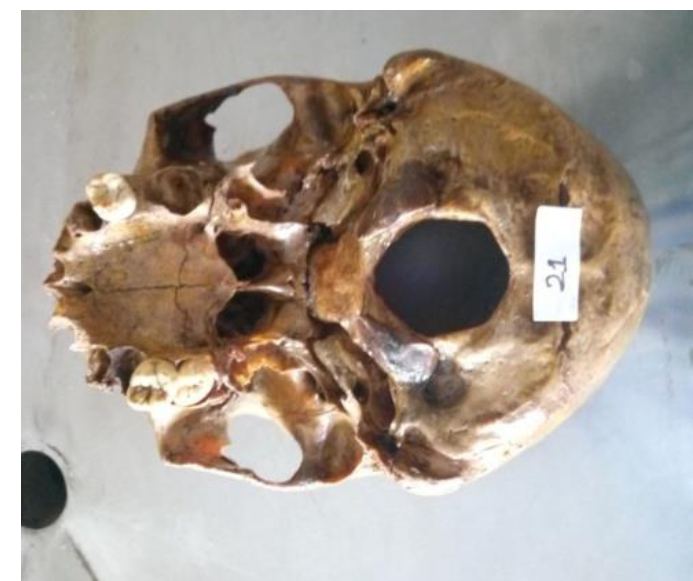

Fig. 5: Hexagonal shape of FM 


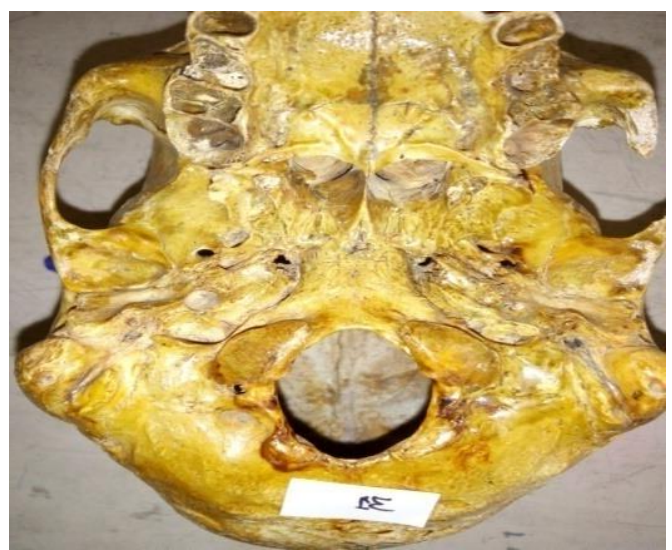

Fig. 6: Oval shape of FM

\section{Statistical analysis}

The morphometric data were calculated statistically using SPSS software version 17 program and appropriate test were applied. The mean \& standard deviation of each dimensions along with $\mathrm{p}$ value were also calculated.

\section{Results}

The morphometric data of foramen magnum such as anteroposterior, transverse \& area were recorded and are represented in tabulated form. The distribution of various types of shapes were assessed macroscopically in foramen magnum and represented is represented in tabular form.

Table 1: Showing the morphometric dimensions of foramen magnum

\begin{tabular}{|l|c|c|c|c|}
\hline Parameter & $\begin{array}{c}\text { Dry Skull (mm) } \\
\text { (Mean } \pm \text { SD) }\end{array}$ & Max & Min & p value \\
\hline AP & $34.08 \pm 2.25$ & 36.25 & 32.25 & $<0.001$ \\
\hline TR & $28.17 \pm 2.85$ & 30.75 & 25.75 & $<0.001$ \\
\hline AREA & $757.41 \pm 115.09$ & 1030.45 & 634.65 & $<0.001$ \\
\hline
\end{tabular}

Table 1 shows the parameters of foramen magnum- the mean anteroposterior diameter is $34.08 \mathrm{~mm}$ ranging from $36.25-32.25$ $\mathrm{mm}$ with standard deviation of 2.25 \& mean transverse diameter is $28.17 \mathrm{~mm}$ ranging from $30.75-25.75 \mathrm{~mm}$ with standard deviation of 2.85 .The mean area is $757.41 \mathrm{~mm}$ ranging from $1030.45-634.65 \mathrm{~mm}^{2}$ with standard deviation of $115.09 \mathrm{~mm} . \mathrm{p}$ value is $<0.001$ which is statistically significant.

Table 2: Showing the various types of shapes of foramen magnum

\begin{tabular}{|l|c|c|}
\hline Shapes & Dry skull & Percentage (\%) \\
\hline Oval & 29 & 58 \\
\hline Irregular & 00 & - \\
\hline Hexagonal & 05 & 10 \\
\hline Tetragonal & 00 & - \\
\hline Pentagonal & 02 & 4 \\
\hline Round & 06 & 12 \\
\hline Diamond & 08 & 16 \\
\hline
\end{tabular}

In this study Table 2 shows the frequency of distribution of types of shapes in foramen magnum is oval $58 \%$, hexagonal $10 \%$, pentagonal $4 \%$, round $12 \%$ and diamond $16 \%$.

Table 3: Comparison of distribution of morphological types of shapes in foramen magnum of dry skull with previous studies.

\begin{tabular}{|c|c|c|c|c|c|}
\hline $\begin{array}{l}\text { Types of foramen } \\
\text { Magnum }\end{array}$ & $\begin{array}{c}\text { Murshed et } \\
\text { al }^{12}\end{array}$ & $\begin{array}{c}\text { Radhakrishna et } \\
\text { al }^{13}\end{array}$ & $\begin{array}{c}\text { P. Chethan et } \\
\text { al }^{10}\end{array}$ & $\begin{array}{c}\text { Radhika } \\
\text { P.M. }^{14}\end{array}$ & $\begin{array}{l}\text { Present } \\
\text { Study } 50\end{array}$ \\
\hline Oval & $9(8.1 \%)$ & $39(39 \%)$ & $8(15.1 \%)$ & $60(40 \%)$ & $29(58 \%)$ \\
\hline Round & $24(21.8 \%)$ & $28(28 \%)$ & $12(22.6 \%)$ & $30(20 \%)$ & $6(12 \%)$ \\
\hline Tetragonal & $14(12.7 \%)$ & $19(19 \%)$ & $10(18.9 \%)$ & $9(6 \%)$ & - \\
\hline Hexagonal & $19(17.2 \%)$ & - & $3(5.6 \%)$ & $9(6 \%)$ & $5(10 \%)$ \\
\hline Irregular & $22(19.9 \%)$ & - & $8(15.1 \%)$ & $24(16 \%)$ & - \\
\hline Pentagonal & - & - & - & - & $2(4 \%)$ \\
\hline Diamond & - & - & - & - & $8(16 \%)$ \\
\hline
\end{tabular}

This table shows that the data obtained from present study was compared with reports from different authors. According to Murshed et al, ${ }^{12}$ Chetan et al,${ }^{10}$ Radakrishan et al ${ }^{13}$ shape is mainly rounded type while in our study \& study done by Radhika et $\mathrm{al}^{14}$ shape is mainly oval type. 
Table 4: Comparison of morphological parameters of foramen magnum in various studies.

\begin{tabular}{|l|c|c|}
\hline \multicolumn{1}{|c|}{ Authors And Year } & $\begin{array}{c}\text { Antero-posterior } \\
\text { diameter in (mm) }\end{array}$ & Transverse Diameter In (mm) \\
\hline Coin and Malkasion (1971) & 34 & 29 \\
\hline Olivier (1975) & 35.7 & 30.34 \\
\hline Routal et al (1984) & 35.5 & 29.6 \\
\hline Catalina et al (1987) & 36.2 & 31.1 \\
\hline Lange (1991) & 35.33 & 29.6 \\
\hline Sendemir et al (1994) & 35.6 & 29.9 \\
\hline Berge and Bergmenn (2001) & 33.8 & 28.3 \\
\hline Murshed et al (2003) & 35.9 & 30.45 \\
\hline Muthukumar et al (2005) & 33.3 & 27.9 \\
\hline Kizilkant et al (2006) & 34.8 & 29.9 \\
\hline Gapert et al (2008) & 35.91 & 30.51 \\
\hline Suazo G.et al (2009) & 36.05 & 30.05 \\
\hline Milhorat et al (2010) & 32.5 & 30.8 \\
\hline Chethan et al (2011) & 31 & 25.2 \\
\hline Damiani et al (2012) & 34.78 & 28.69 \\
\hline Radhakrishna et al (2012) & 34.04 & 28.63 \\
\hline Kanchan et al (2013) & 34.51 & 28.98 \\
\hline Santhosh et al (2013) & 34.37 & 28.98 \\
\hline Radhika P.M et al (2014) & 35.3 & 29.4 \\
\hline Muralidhar et al (2014) & 33.4 & 28.5 \\
\hline Anil Kumar et al (2015) & 36.78 & 30.05 \\
\hline Vishal Ramesh Jasuja (2016) & 34.13 & 27.82 \\
\hline Ayfer Metin et al (2017) & 33.86 & 29.48 \\
\hline Present study (2018) & 34.08 & 28.17 \\
\hline & & \\
\hline
\end{tabular}

The above table shows that the data obtained from present study compared with reports from different authors. The measurement of anteroposterior dimension \& transverse dimensions are same as done by Radhakrishna et al, ${ }^{13}$ Damiani et al ${ }^{15}$ \& Santosh et al. ${ }^{16}$

Table 5: Interpretation \& analysis of Area measurement with other studies on foramen magnum

\begin{tabular}{|l|c|}
\hline Authors and years & Foramen magnum area (mm2) \\
\hline Teixeira (1982) & 963.73 \\
\hline Routal et al (1984) & 819 \\
\hline Catalina et al (1987) & 888.4 \\
\hline Gunay and Altinkok (2000) & 909.91 \\
\hline Murshed et al (2003) & 931.7 \\
\hline Acer et al (2006) & 760 \\
\hline Gapert et al (2008) & 862.41 \\
\hline Milhorat et al (2010) & 787.7 \\
\hline Ukoha et al (2011) & 857 \\
\hline Raghavendra et al (2012) & 811.67 \\
\hline Burdan et al (2012) & 877.4 \\
\hline Singh and Talwar(2013) & 733 \\
\hline Mularidhar et al (2014) & 748.6 \\
\hline Anil Kumar et al (2015) & 876.88 \\
\hline AyferMetin et al (2017) & 8,17 \\
\hline Present study (2018) & 757.41 \\
\hline
\end{tabular}

In our study of foramen magnum area measurement is similar to study done by Muralidhar et al, ${ }^{3}$ Singh \& Talwar ${ }^{17} \&$ Acer et $\mathrm{al}^{18}$ 


\section{Discussions}

Foramen magnum is a passage between the cranial cavity and vertebral canal. It is formed by interaction of bony ligaments \& muscular structures forming the complex cranio-vertebral junction. The anatomical knowledge of foramen magnum is helpful for manifestation of clinical sign and symptoms in various cranio-cervical disease. ${ }^{19}$ Bony parameters of foramen magnum is also needed for trans-condylar approach. Understanding the importance of foramen magnum the findings of the present study were compared with previous studies. In our study of foramen magnum the mean antero-posterior \& transverse diameters in 50 skulls are $34.08 \pm 2.25 \mathrm{~mm}$ and $28.17 \pm 2.85 \mathrm{~mm}$ similar to study on Brazilian skulls which also shows that the mean Antero-posterior diameter was $35.22 \pm 3.3 \mathrm{~mm}$ and the mean Transverse diameter was $30.3 \pm 2.0 \mathrm{~mm}$. This morphometric study of foramen magnum showed slightly less dimensions than the study done on 100 Nigerian skulls in 2011, which showed a mean Antero-posterior diameter of $36.2 \pm 2.3 \mathrm{~mm}$ and a transverse diameter of $30.0 \pm 2.5 \mathrm{~mm} .{ }^{20}$ This shows that this variations in study is due to racial differentiation. Morphometric measurement of foramen magnum revealed that antero-posterior diameter is more than the transverse diameter in our study and similar finding reported by Olivier. ${ }^{21}$ Ford also reported that during prenatal period length of foramen magnum increases rapidly than the width which also explained that herniation of cerebellar tonsil is due to large anteroposterior diameter of foramen magnum. ${ }^{22}$ The measurement of anteroposterior $\&$ transverse diameter in our study same as study done by Radhakrishna et al, ${ }^{13}$ Damiani et al ${ }^{15} \&$ Santosh et al. ${ }^{16}$

Measurement of area on foramen magnum in the study is $757.41 \mathrm{~mm}^{2}$ which is similar to morphometric study done by Muralidhar et al ${ }^{3}$ Singh \& Talwar $^{17}$ \& Acer et al. ${ }^{18}$ Uthmant et $\mathrm{a}^{23}$ also reported that foramen magnum area is best discriminant parameter for sex determination with an accuracy of $69.3 \%$. Foramen magnum undergoes various evolutionary changes due to its different osteological features. ${ }^{24}$ There are great variation in morphological shapes of foramen magnum. The morphological variation of Foramen magnum found in the our study were Oval $48 \%$, Rounded 19\%, Hexagonal 9\%, Pentagonal 12\% Diamond $9 \%$ and Irregular $3 \%$ shapes. Zaidi \& Dayal ${ }^{25} \&$ Radhika et $\mathrm{al}^{14}$ also observed oval as main type $64 \%$. Knowledge of this morphological shape is very important as for surgeons as it is difficult to explore anterior portion of foramen magnum in ovoid type. In some other study of Mushed et al, ${ }^{12}$ Chetan et al, ${ }^{10}$ Radakrishan et al ${ }^{13}$ the round shape is commonly observed. There is great variations regarding literature available on the morphological dimensions of foramen magnum. The present study gives a morphometric reference of various types of foramen magnum in Indian population \& its clinical significance. This type of prospective studies will help to approach for brain stem lesions which are increasing in recent trend.

\section{Conclusion}

The morphometric knowledge regarding foramen magnum is very important for various neurological \&surgical procedures of posterior cranial fossa. The study of foramen magnum provide supportive findings for forensic experts in estimation of sex of fragmented, incomplete or damaged dry human skulls.

This type of morphometric study also gives us significant parameters which should be applied during cranio-vertebral surgery\& to determine feasible transcondylar approaches to prevent complications like hemorrhage and injury to vital structures going through it. Therefore, at last we conclude that the comparative evaluations on data of foramen magnum showed significant difference between various parameters, so further studies are required on it due to its great clinical significance.

\section{Source of funding}

None.

\section{Conflict of interest}

None.

\section{References}

1. Standarding S. Gray's anatomy. The anatomical basis of clinical practice. 39th ed. London: Elsevier Churchill Livingstone; 2005:460.

2. Manoel C, Prado FB, Caria PHF, Groppo FC. Morphometric analysis of the foramen magnum in human skulls of brazilian individuals: its relation to gender. Braz J Morphol Sci 2009;26(2):104-8.

3. Muralidhar P Shepur, Magi M, Nanjundappa B, Pavan P Havaldar, Premalatha Gogi, Shaik Hussain Saheb.

Morphometric analysis of foramen magnum. Int $J$ Anat Res 2014;2(1):249-55.

4. Gautam Kanodia, Vijay Parihar, Yad R Yadav, Pushp R Bhatele and Dhananjay Sharma. Morphometric analysis of posterior fossa and foramen magnum. $J$ Neurosci Rural Pract 2012;3(3):261-6.

5. Tanujkanchan, Anadigupta, and kewalkrishan. Craniometric analysis of foramen magnum for estimation of sex. Int $J$ Medi Health Biomed Pharmace Engin 2013;7(7):111-3.

6. Suazo G I C, Russo P P, Zavando M D A, Smith R L. Sexual dimorphism in the foramen magnum dimensions. Int $J$ Morphol 2009;27(1):21-3.

7. Edwards K, Viner M D, Schweitzer W, Thali M J. Sex determination from the foramen magnum. J Foren Radio Imag 2013;1(4):186-92

8. Furtado SV, Thakre DJ, Venkatesh PK, Reddy K, Hegde AS. Morphometric analysis of foramen magnum dimensions and intracranial volume in pediatric chiari I malformation. ACTA Neurochir (WEIN) 2010:152:221-7.

9. Deepak S Howale, Anil Bathija, Sudarshan Gupta, Pandit D P. Correlation between cranial index and foramen magnum index in human dried skulls. GJRA 2014;3(1):3-6.

10. Chethan P, Prakash K G. Morphological analysis and morphometry of foramen magnum: an anatomical investigation. Turk Neurosurg 2012:22(4):416-9.

11. Anil Kumar, Mitesh Dave, Sanam Anwar. Morphometric evaluation of foramen magnum in dry human skulls. Int $J$ Anat Res 2015;3(2):1015-23.

12. Murshed KA, Emine A, Tuncer I: Morphometric evaluation of the foramen magnum and variations in its shape: a study of CT images of normal adults. Turk J Sci 2003;33:301-6. 
13. Radhakrishna S.K. Shivarama C.H. Ramakrishna A. Bhagya B. Morphometric analysis of foramen magnum for sex determination in South Indian population. NUJHS 2012;2(1):20-2.

14. Radhika P.M, Shailaja Shetty, Prathap K.J, C. Sheshgiri, Jyothi K.C. Morphometric study of the foramen magnum in adult human skulls in Indian population. Asian J Med Clin Sci 2014;3(2):68-72.

15. Damiani Borelli NS, Melo HJF, Lima RS, Nobeschi. Morphometry and spatial correlation of the foramen magnum and spinal cord through MRI. J Morphol Sci 2012;29(2):87-90.

16. Santhosh CS, Vishwanathan KG, Ashok Gupta, Siddesh RC, Tejas J. Morphometry of the Foramen Magnum: An Important Tool in Sex Determination. Research and Reviews. J Ed Health Sci 2013;4(2):88-91.

17. Singh and Talwar. Morphometric analysis of foramen magnum in human skull for sex determination. Hum Biol Rev 2013;2(1):29-41.

18. Acer N, Sahin B, Ekinci N, Ergür H, Basaloglu H. Relation between intracranial volume and the surface area of the foramen magnum. J Craniofac Surg 2006;17:326-30.
19. Nelson FW, Horton WA, Wassman ER. Computerized tomography of the Foramen magnum; A chondroplastic values compared to normal standards. Am J Med Genet 1985;35:70512.

20. Ukoha U. Sexual Dimorphism in the Foramen Magnum of Nigerian. Adult Int J Biol Med Res 2011;2(4):878-81.

21. Olivier G. Biometry of the human occipital bone. J Anat 1975;120:507-18

22. Ford HER. Growth of foetal skull. J Anat 1956;90:63-72.

23. Uthman AT, Rawi NA and Timini JA. Evaluation of foramen magnum gender determination using helical CT scanning. Dentomaxillofac Radiol 2012;14:197-202.

24. Nevell L, Wood B. Cranial base evolution with in the hominin clade. J Anat 2008;212;455-68.

25. Zaidi SH, Dayal SS. Variations in shape of Foramen magnum in Indian skulls. Anat Anz Jena 1988;167:338-40. 